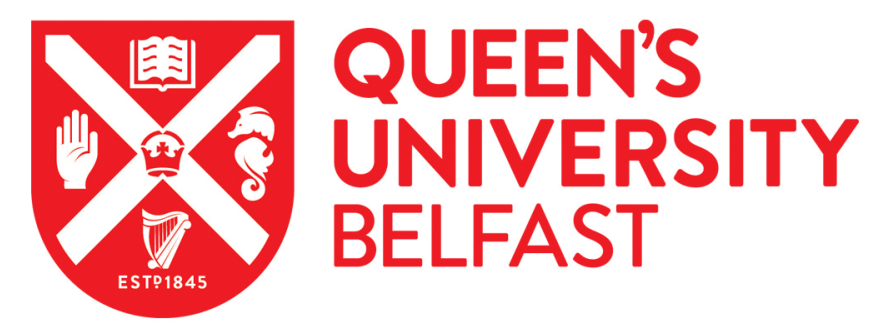

\title{
Exploring the Influence of Temporal Factors on Age Differences in Working Memory Dual Task Costs
}

Rhodes, S., Doherty, J. M., Jaroslawska, A., Forsberg, A., Belletier, C., Naveh-Benjamin, M., Cowan, N., Barrouillet, P., Camos, V., \& Logie, R. H. (2021). Exploring the Influence of Temporal Factors on Age Differences in Working Memory Dual Task Costs. Psychology and aging, 36(2), 200-213.

https://doi.org/10.1037/pag0000531

Published in:

Psychology and aging

Document Version:

Peer reviewed version

Queen's University Belfast - Research Portal:

Link to publication record in Queen's University Belfast Research Portal

Publisher rights

Copyright 2020 American Psychological Association. This work is made available online in accordance with the publisher's policies. Please refer to any applicable terms of use of the publisher.

\section{General rights}

Copyright for the publications made accessible via the Queen's University Belfast Research Portal is retained by the author(s) and / or other copyright owners and it is a condition of accessing these publications that users recognise and abide by the legal requirements associated with these rights.

Take down policy

The Research Portal is Queen's institutional repository that provides access to Queen's research output. Every effort has been made to ensure that content in the Research Portal does not infringe any person's rights, or applicable UK laws. If you discover content in the Research Portal that you believe breaches copyright or violates any law, please contact openaccess@qub.ac.uk. 
Exploring the influence of temporal factors on age differences in working memory dual task costs

Stephen Rhodes ${ }^{1}$, Jason M. Doherty ${ }^{2}$, Agnieszka J. Jaroslawska ${ }^{3}$, Alicia Forsberg ${ }^{4}$, Clément Belletier $^{5}$, Moshe Naveh-Benjamin ${ }^{4}$, Nelson Cowan ${ }^{4}$, Pierre Barrouillet ${ }^{6}$, Valérie Camos ${ }^{7}, \&$ Robert H. Logie ${ }^{2}$

${ }^{1}$ Rotman Research Institute, Baycrest Hospital

${ }^{2}$ The University of Edinburgh

${ }^{3}$ Queen's University Belfast

${ }^{4}$ University of Missouri

${ }^{5}$ Clermont Auvergne University

${ }^{6}$ University of Geneva

${ }^{7}$ University of Fribourg

Draft: 21 September 2020 
Data, code, and materials are available at https://osf.io/p93af/. Parts of this work will be presented at the 2020 meeting of the Psychonomic Society. This work was funded by the Economic and Social Research Council (ESRC) grant ES/N010728/1 ('Working Memory Across the Adult Life-Span: An Adversarial Collaboration'). We thank Reed Decker for assistance with data collection. This manuscript was written using the papaja package (Aust \& Barth, 2020).

Correspondence concerning this article should be addressed to Stephen Rhodes, 3560 Bathurst Street, Toronto ON, M6A 2E1. E-mail: srhodes@research.baycrest.org 


\begin{abstract}
Working memory is defined by many as the system that allows us to simultaneously store information over brief time periods while engaging in other information processing activities. In a previous study (Rhodes et al., 2019) we found that retention of serially presented letters was disrupted by the introduction of an arithmetic processing task during a 10 second delay period. Importantly, the magnitude of this dual task disruption increased with age from 18 to 81 . The demands of each task were adjusted prior to dual task so that age differences did not reflect baseline differences in single task performance. Motivated by these findings, theories of working memory, and additional analyses of processing reaction times from this previous experiment, we report two experiments, using the same tasks and adjustment procedure, attempting to modulate the magnitude of age differences in dual task effects via manipulations focused on time for encoding to-be-remembered material. Providing a delay prior to processing activities, to facilitate switching between the two tasks, did not modulate age differences. Neither did separating the to-be-remembered material temporally, to allow for the creation of more distinct representations. These findings provide two replications of our initial finding and suggest that age differences in working memory dual tasking are not due to limitations in the speed of encoding.
\end{abstract}

Keywords: Working Memory; Cognitive Aging; Dual Task; Switching; Interference Word count: 8300 (approx.) 
Exploring the influence of temporal factors on age differences in working memory dual task costs

For many, working memory is the system that supports the storage of a small amount of information while other information processing is engaged (for overviews, see, Baddeley, 2007; Cowan, 2017; Logie, Camos, \& Cowan, 2021). Often the demand to simultaneously store and process information results in a cost to memory for the stored information and/or to performance on the concurrent processing task, relative to when these tasks are performed in isolation. Exploring these dual task costs, and the conditions that potentially modulate their magnitude, has informed theorizing about working memory for decades (e.g., Baddeley \& Hitch, 1974; Barrouillet \& Camos, 2015; Cowan, Saults, \& Blume, 2014; Doherty \& Logie, 2016; Doherty et al., 2019; Logie, 1995; Oberauer, Lewandowsky, Farrell, Jarrold, \& Greaves, 2012).

A related literature has also addressed adult age differences in the magnitude of dual task costs for storage and processing tasks. Many of these studies find that age differences in performance are larger when storage and processing tasks are combined relative to when they are performed in isolation (e.g., Bier, Lecavalier, Malenfant, Peretz, \& Belleville, 2017; Bopp \& Verhaeghen, 2005; McNab et al., 2015; Rhodes et al., 2019). Nevertheless, there are also findings that suggest possible boundary conditions, under which age differences are not significantly larger in tasks combining storage and processing. One of these conditions in particular, that we discuss in more detail below, is when the difficulty of each task has been adjusted to account for individual differences in single task performance before the two are combined (e.g., Anderson, Bucks, Bayliss, \& Sala, 2011; Baddeley, Logie, Bressi, Della Sala, \& Spinnler, 1986; Logie, Cocchini, Della Sala, \& Baddeley, 2004). In a recent meta-analysis, Jaroslawska and Rhodes (2019) found that there was, indeed, a small but disproportionate age difference in memory task performance when simultaneous processing was required, relative to when there was no processing. However, when considering age differences in dual 
task costs, there was substantial residual heterogeneity in effect sizes across studies. This, along with the lack of significant age-related dual task costs in some studies (see Logie, Horne, \& Pettit, 2015 for a review), points to a real need for experimental work examining potential modulating factors. Here we choose to focus on a paradigm in which robust age differences in dual task performance have been identified (Rhodes et al., 2019). In the two experiments reported here we assess the role of encoding time in modulating the magnitude of dual task costs and age differences in these costs. Below we discuss our previous study in more detail and present some additional analyses of the data from Rhodes et al. (2019) that further serve to motivate our manipulations.

\section{Age differences in working memory dual tasking under adjusted task difficulty}

In our previous experiment (Rhodes et al., 2019) we aimed to assess age differences in working memory dual tasking under circumstances that previous studies had suggested might result in no disproportionate age-related dual task cost. We also assessed how our results could be reconciled with three theoretical frameworks for understanding working memory (see the original article and Cowan et al., 2020 for a detailed discussion of this aspect).

To summarize our approach, we asked 164 participants aged between 18 and 81 to perform a simple serial order letter recall task and a processing task, requiring the verification of single digit sums (e.g., " $4+5=11$ ?"). These tasks were performed either in isolation, as single tasks, or together as a dual task (see Figure 1). In the memory task participants were presented with a sequence of consonants either visually on screen or auditorily over headphones. Following an $11 \mathrm{~s}$ interval, participants were asked to recall the consonants in serial order. The manner of recall, typed or spoken, depended on the format of presentation but this factor had no clear impact on our results regarding age differences in performance, so we will ignore this aspect here. The arithmetic processing task presented a variable number of single digit sums, one at a time within a 10 s period, and participants 
had to press one of two buttons on a button box according to whether the solution presented was correct or incorrect. When the two tasks were performed concurrently the processing task was presented during the retention interval of the memory task with a $1 \mathrm{~s}$ blank interval between the final letter and the first processing problem.

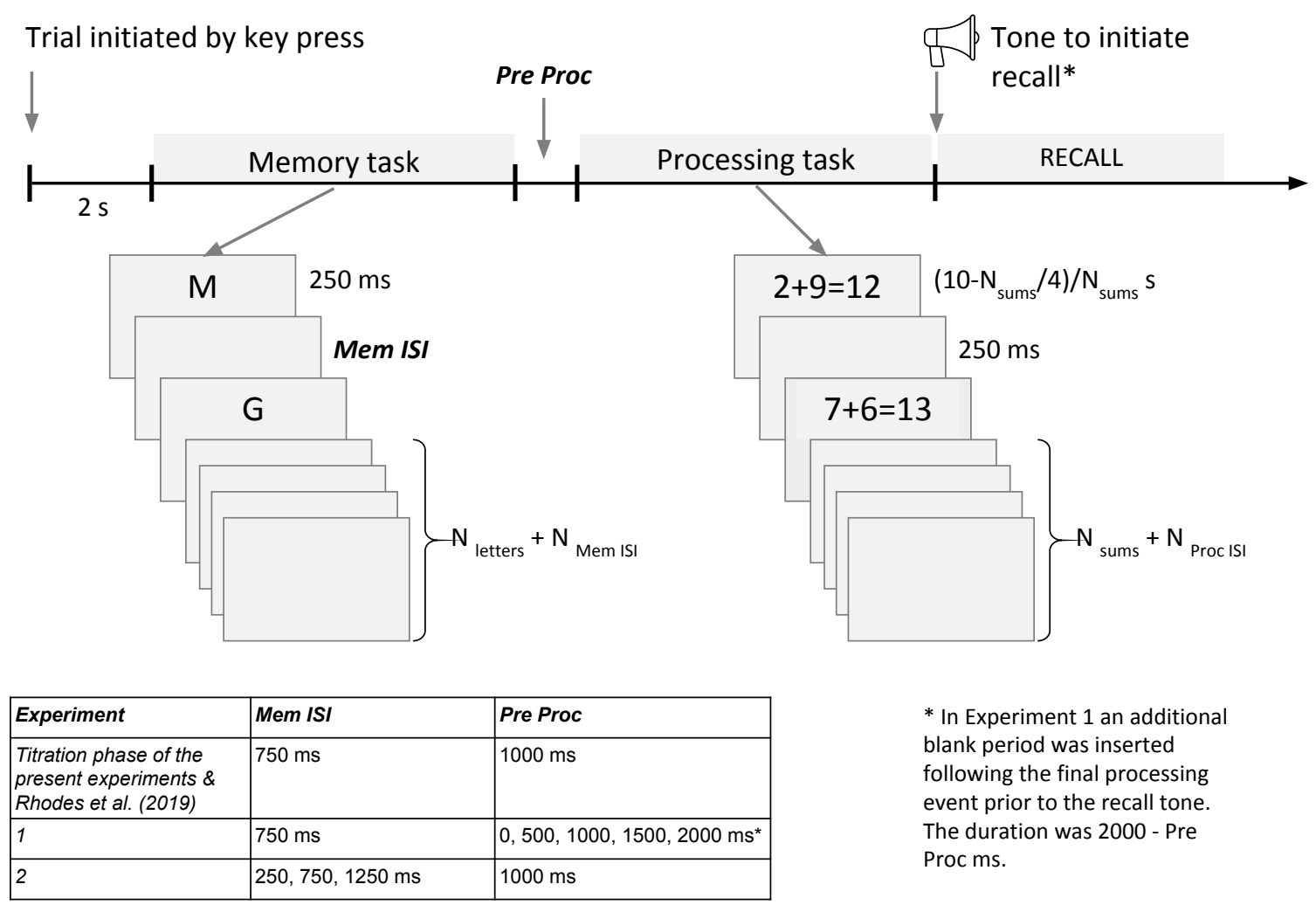

Figure 1. The general procedure used in Rhodes et al., (2019) and the present experiments. The two experiments reported here manipulated temporal factors, as shown in the table. Pre proc $=$ amount of time inserted between the final to-be-remembered item and the onset of the first arithmetic problem; Mem ISI = amount of time a blank screen was presented for following each letter.

Previous work on this topic has suggested that age differences in dual task performance are not observed when the difficulty of each task is adjusted to account for individual differences in single task performance, in particular when recall of a digit sequence is combined with concurrent perceptuo-motor tracking (e.g., Logie et al., 2004). This 
adjustment of difficulty is often referred to as "titration" in this literature and we use this term throughout. Wanting to test the generality of this finding in a large sample spanning the adult life-span, in Rhodes et al. (2019) we titrated the level of difficulty of the memory and arithmetic tasks at the beginning of the experimental session. Participants performed a staircase-like procedure in which the number of to-be-remembered letters or the number of to-be-verified sums (within $10 \mathrm{~s}$ ) was varied until the participant was approximately $80 \%$ accurate (this is described in more detail in the method section below). This procedure was also important in providing a common single task baseline for participants of different ages, which facilitates the interpretation of any age differences in dual task performance (see Somberg \& Salthouse, 1982).

Once task demand was titrated, another important aspect of our design was that, during the dual task phase of the experiment, the tasks were performed under different incentives. Across separate trial blocks, participants were provided with weighted feedback and a small financial reward that either emphasized performance on the memory task over the arithmetic processing task or vice versa (or both tasks equally). Our interest in this manipulation was the assumption that, to the extent that the two tasks draw on overlapping cognitive resources, performance should trade off between the two tasks (i.e., performance on one task should improve with increasing emphasis and decrease on the other task). This was intended to discriminate theories of working memory with some degree of resource sharing between storage and processing activities (Barrouillet \& Camos, 2015; Cowan, 2010) and those with a greater amount of domain specificity (Logie, 2011, 2016). The original article describes this theoretical distinction in further detail.

The main findings in Rhodes et al. (2019) were that performance on the memory task was substantially impaired under dual task conditions, relative to single task. In other words, regardless of the emphasis placed on a particular task, memory performance was poorer when the processing task was presented during the retention interval (see also, Doherty et al., 
2019). Interestingly, the magnitude of this "concurrence cost" (Navon \& Gopher, 1979) increased more-or-less linearly with age, such that the recall performance of older adults was impaired to a greater extent by concurrent processing. Performance on the processing task did not show the same general drop under dual task conditions, an asymmetry that we have found in other studies with younger adults (Doherty et al., 2019); however, the two tasks did appear to trade off in response to the weighted feedback. In general, greater emphasis on the memory task produced higher performance for that task and lower performance for processing (and vice versa). Interestingly, the magnitude of this trade off did not vary significantly with age.

\section{Potential for modulating dual task costs}

The findings of our previous experiment suggest that, even under titrated conditions, older participants exhibit a greater cost in their retention of letters in serial order when tasked with concurrent processing (arithmetic) during the retention interval. The present work aimed to explore this finding, and the heterogeneity found in the meta-analysis by Jaroslawska and Rhodes (2019), using both empirically and theoretically motivated manipulations that could conceivably influence the size or presence of this dual task cost. The broader literature on working memory suggests two manipulations to the encoding period of the task that we discuss below. Here we focus on manipulations that do not change the response requirements of the tasks or the stimuli used (Jaroslawska et al., Under review, will report such experiments), as we wanted to build on a circumstance in which a clear age difference is found.

A major reason for focusing on manipulating the timing of the encoding period of the memory task used here is the well known finding that aging has marked effects on the speed of information processing (e.g., Cerella, 1985; Deary, Johnson, \& Starr, 2010). Further, studies looking at individual differences (e.g., Salthouse, 1991; Salthouse \& Babcock, 1991) 
have found that the majority of age related variance in working memory performance can be accounted for by simple measures of processing speed (see Salthouse, 2015 for a review). The wider literature reveals aspects of trial timing that could influence dual task costs and age differences in these costs. In particular, the time between the presentation of the to-be-remembered material and the onset of processing may afford more or less effective switching between the two demands (Chen \& Cowan, 2009; Vergauwe, Camos, \& Barrouillet, 2014). Additionally, the pace of the memory list may influence how fully the information is consolidated into working memory (Tan \& Ward, 2008). Both of these factors could conceivably influence how effectively information is encoded and stored throughout a concurrent processing demand in younger and older adults. In Experiment 1 we focused on the amount of time between list presentation and the onset of processing.

\section{Experiment 1: Time between list presentation and processing task onset}

Vergauwe et al. (2014) used a similar procedure to that used in our aging study (Rhodes et al., 2019), in which to-be-remembered items were presented to younger participants before a processing task was presented during the retention interval. They reported 7 experiments using a range of stimuli and processing tasks, each requiring a speeded choice between two alternative responses. Their main finding of interest to us here is that response times to the first processing item were slowed to a much greater degree by the introduction of a memory load relative to subsequent processing responses (see also Camos et al., 2019; Chen \& Cowan, 2009; Jarrold, Tam, Baddeley, \& Harvey, 2011). One interpretation of this finding is that maintenance activities slow switching to, and engagement with, the decisions required by the processing task (see, e.g., Oberauer, 2005; Vergauwe et al., 2014).

In Vergauwe et al's experiments there was essentially no time separating the final to-be-remembered item and the first processing event. However, in Rhodes et al. the final memory item was followed by a $750 \mathrm{~ms}$ inter-stimulus interval and a further $1 \mathrm{~s}$ interval prior 


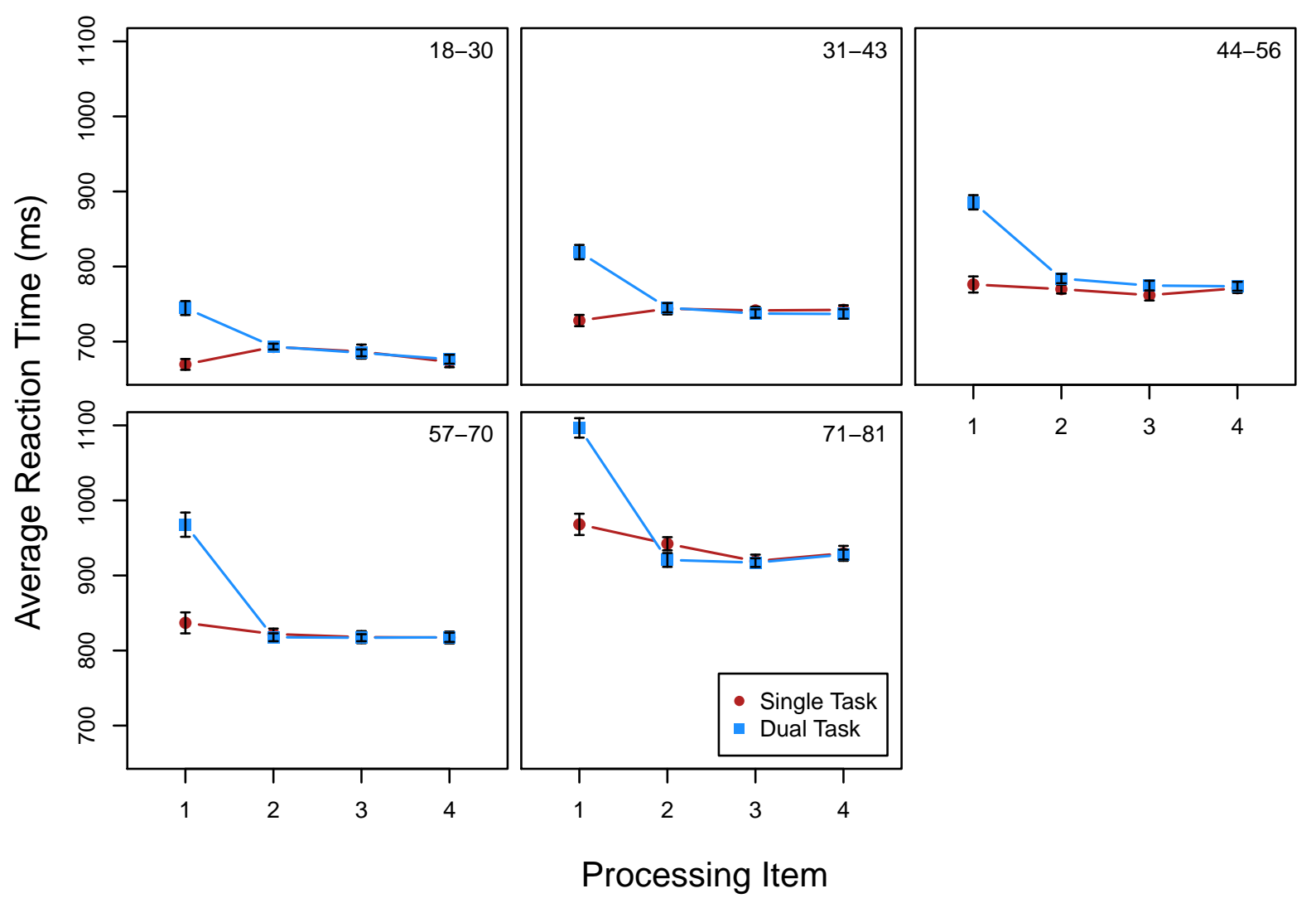

Figure 2. Processing reaction times from Rhodes et al. (2019). Average RT is shown for processing items 1 to 4 under single and dual task conditions for 5 age bands (age ranges given at upper right corner of each panel). Dual task aggregates over conditions with different emphasis placed on memory vs. processing. Error bars are \pm standard error (using the Morey, 2008 correction for within-subjects designs).

to the onset of processing. This was included to provide participants with enough time to fully encode the list and prepare for the processing task. Nevertheless, additional analysis of these data suggest that there may be age-related slowing in switching to the processing task. Figure 2 presents average reaction times for the first four processing events split across different age bands. ${ }^{1}$ As can be seen in this plot, response times to the first processing event

\footnotetext{
${ }^{1}$ The number of processing events presented during the retention interval varied across participants given their titrated level of difficulty. However, all participants saw at least 4 processing events, which is why we focus on those events here.
} 
are much slower under dual task conditions. Further, the degree of this slowing is more extreme in older participants, as confirmed by a significant age by task (single vs. dual) by processing item (first vs. rest) interaction (see the supplement for full details of this analysis). For the youngest group the difference between single and dual task for the first processing item is around $75 \mathrm{~ms}$, whereas for the oldest group this difference is around $427 \mathrm{~ms}$. While there are clear baseline age-differences in response time, we provide evidence in the supplement that older participants' first processing RTs under dual task cannot be explained by overall speed differences under single task. These findings are consistent with recent results reported by Fanuel, Plancher, Monsaingeon, Tillmann, and Portrat (2018) who, using a procedure much more similar to Vergauwe et al. (2014), found that older adults' first processing times were slowed by the introduction of a memory load (1 or 2 spatial locations) and to a greater extent than those of younger adults.

The slowing of the first response under dual task conditions may suggest age-related difficulties in switching to processing following the presentation of the list. It is likely that participants engage in additional processes, such as grouping or chunking of the presented list (e.g., Belletier et al., Under review; Logie, Sala, Laiacona, Chalmers, \& Wynn, 1996), that may serve to make representations less susceptible to disruption from ongoing processing. Older adults appear to be less efficient at this kind of processing (Naveh-Benjamin, Cowan, Kilb, \& Chen, 2007) or they may adopt a different, possibly more time consuming, approach to the task (Chevalère, Lemaire, \& Camos, 2020; Logie, 2018), which may have contributed to their larger dual task cost. Varying the time available for the full encoding and, possibly, strengthening (rehearsal/refreshing) of the to-be-remembered list prior to the onset of processing could conceivably modulate the dual task cost for both memory (overall accuracy) and processing (first RTs) and, more importantly, modulate age differences in these costs. This was assessed in this experiment by varying the delay between the presentation of the letter sequence and the first processing event. 


\section{Method}

Table 1

Participant information for the two experiments reported here.

\begin{tabular}{|c|c|c|c|c|}
\hline & \multicolumn{2}{|c|}{ Experiment 1} & \multicolumn{2}{|c|}{ Experiment 2} \\
\hline & Older & Younger & Older & Younger \\
\hline$N$ & 41 & 40 & 54 & 54 \\
\hline$N_{\text {female }}$ & 26 & 27 & 40 & 39 \\
\hline Age (years) & $72.29(4.05)$ & $21.70(2.95)$ & $70.70(4.48)$ & $22.28(3.43)$ \\
\hline $\mathrm{MoCA}$ & $26.37(2.26)$ & $27.23(1.64)$ & $27.43(2.33)$ & - \\
\hline Memory Span & $5.37(0.94)$ & $6.30(1.16)$ & $5.70(1.11)$ & $6.37(1.25)$ \\
\hline Processing Span & $8.22(1.67)$ & $8.82(1.81)$ & $7.94(1.86)$ & $9.09(1.94)$ \\
\hline
\end{tabular}

Note: Mean age, Montreal Cognitive Assessment (MoCA) scores, and spans are given with standard deviations in parentheses. Younger participants did not complete the MoCA in Experiment 2.

Participants. Participants were recruited at both the University of Missouri-Columbia (US) and the University of Edinburgh (UK). The procedures for each of the experiments reported here were approved by the University of Edinburgh Psychology Research Ethics Committee and the University of Missouri IRB. Forty one older adults (aged 67-84; 20 in the US and $21 \mathrm{UK}$ ) were recruited from established pools of individuals willing to take part in experiments. Forty younger participants (aged 18-29; 20 at each site) were recruited from the local community and mainly comprised of students and staff at the respective universities (see Table 1). Participants received a base honorarium of $£ 12$ or $\$ 15$ for taking part with up to an additional $£ 4$ or $\$ 5$ depending on task performance (see below).

Our sample size per group was determined by time constraints for testing but we note that our group size is as large or larger than approximately 85\% (96\% for Experiment 2) of 
studies on this topic included in a recent meta-analysis (Jaroslawska \& Rhodes, 2019). Further, our analysis approach, described below, allows us to state evidence for or against particular effects of interest, as well as indicating when the data are indeterminate.

To be included in the experiment participants reported being fluent speakers of English with no history of neurological damage, no problems with hearing, and no problems with vision (unless corrected). To ensure that the older participants show no evidence of cognitive dysfunction incommensurate with normal aging, we used the Montreal Cognitive Assessment (MoCA; Nasreddine et al., 2005) as a screening measure (see Table 1 for scores). Prior to the experiment we set a score of $\leq 20$ as grounds for exclusion from the study as this score has been found to relate to poor global performance on a battery of neuropsychological tests (Waldron-Perrine \& Axelrod, 2012). The recommended cut off of 26 was not used as previous work suggests that this leads to a high rate of false positives (Rossetti, Lacritz, Cullum, \& Weiner, 2011). An additional criteria for exclusion was titrated span in either the memory or processing task of less than 3 items (see below for more detail on the titration procedure). We planned that any excluded participants would be replaced at the respective site but no participants needed to be excluded in this experiment.

Stimuli and Apparatus. Stimuli were presented on a grey background $(R=G=$ $\mathrm{B}=128$ ) via a 23" Lenovo ThinkVision T2324p monitor with a $60 \mathrm{~Hz}$ refresh rate. Memory items were selected from a pool of 18 letters excluding vowels, as well as the letters "w", "y", and "z". Each processing item was a sum of single digits of the form, $\mathrm{x}+\mathrm{y}=\mathrm{z}$ ? ( $\mathrm{z}$ could be double digit). Both the memory and processing stimuli were presented in the "Lucida Console" font with a height of $1.3^{\circ}$ of visual angle at an approximate viewing distance of 60 cm. Participants responded to the processing task via a button box (www.blackboxtoolkit.com) and recalled letters using a standard qwerty keyboard. The experimental procedure was programmed in PsychoPy (Peirce et al., 2019). The experiment programs, data, and analysis scripts for all experiments are available at https://osf.io/p93af/. 
Task procedures. We used the same memory and processing tasks as our previous experiment (Rhodes et al., 2019; see Figure 1). Each trial was initiated when the participant pressed one of two response box buttons. For the memory task this was followed by a $2 \mathrm{~s}$ blank interval before presentation of the first to-be-remembered letter. Letters were presented sequentially on screen for $250 \mathrm{~ms}$ and followed by a $750 \mathrm{~ms}$ blank interval. The number of letters presented was not fixed across participants, as it was set by the titration procedure described below. When the memory task was performed in isolation the final letter was followed by a $1 \mathrm{~s}$ blank interval and then a solid circle appeared on the screen five times at a rate of $1750 \mathrm{~ms}$ on and $250 \mathrm{~ms}$ off (i.e., $11 \mathrm{~s}$ total retention interval). This circle served as a placeholder for the processing task. Following this interval a $400 \mathrm{~Hz}$ tone was played to cue participants to recall the letters in the order presented using the keyboard. To acknowledge responses, each recalled item appeared on the screen for $500 \mathrm{~ms}$, or until another key was pressed. Mistakes could not be corrected and participants could type "0" (zero) to "pass" on a letter.

In the processing task, when performed by itself, each trial began with a placeholder for the memory task in which five filled diamond characters (subtending $1.3^{\circ}$ ) appeared sequentially for $250 \mathrm{~ms}$ each with a $750 \mathrm{~ms}$ blank ISI. The last placeholder was followed by an additional $1 \mathrm{~s}$ interval prior to the first processing item. Each item was a sum of two single digits where the answer given was either correct or deviated by \pm 1 (e.g., $5+7=11$ or $5+7=13$ ). Participants responded by either pressing a button marked with a check symbol (right hand), to indicate that the sum was correct, or by pressing a button marked with a cross (left hand), to indicate that it was incorrect. The number of sums presented during the 10 s processing phase was not fixed, but determined by the titration procedure explained below. Each sum appeared on screen for $(10-N / 4) / N$ s, where $N$ is number of sums to verify, with a $250 \mathrm{~ms}$ blank interval following each sum. A response was accepted for a given sum from its onset to the onset of the next sum. 
In dual task blocks the two tasks were combined with the processing task being presented during the retention interval following presentation of the last to-be-remembered letter (see Figure 1). As described below, the amount of time separating the letter sequence and the first processing event was manipulated in this experiment.

Structure of the testing session. Each participant completed one session lasting approximately 90 minutes. The session consisted of a titration phase and the main experimental phase.

The purpose of the titration phase was to find a level of task demand where the participant was approximately $80 \%$ correct. This measure of "span" was used to set the level of difficulty in the second phase of the experiment. For each task this phase involved a staircase like procedure that was started at 5 items (i.e., either 5 letters to memorize or 5 sums to verify). Each level consisted of two trials with a given number of items and if the participant was able to achieve $\geq 80 \%$ accuracy across these two trials an additional item was added for the next level (pair of trials). If performance was $<80 \%$ an item was taken away to reduce difficulty. This continued until the participant had completed at least 8 levels. If the number of items on the 8th level was the largest reached by the participant and the level was passed the sequence continued until a level was failed, otherwise the titration procedure stopped at level 8 . The resulting span was the longest sequence that the participant passed the $80 \%$ criterion. The order in which the memory and processing task were titrated was counterbalanced across participants.

In the main experimental phase the participants completed the memory and processing tasks, set at their span levels, as single and dual tasks. There were 7 blocks in this phase each beginning with 2 practice trials followed by 8 trials used in analysis. The first and last blocks were single task measures in which either the memory or processing task was performed in isolation (order counterbalanced). In the remaining 5 dual task blocks we systematically varied the delay following the presentation of the final letter before the onset 
of the first processing item. The different post sequence delays $(0,500,1000,1500$, and 2000 ms) were counterbalanced according to a Latin square. To ensure that the retention interval was the same duration across all 5 dual task blocks we also included a delay following the final processing item with a duration of $2000 \mathrm{~ms}$ minus the post sequence delay. Thus in this experiment the retention interval was 1 s longer than that in Rhodes et al. (2019) to accommodate this manipulation.

As done in our previous experiment, participants were given feedback on their performance following each trial in the main phase. Bar plots were presented showing the number of "points" earned on a particular trial out of a maximum of 100. In single task blocks the number of points earned was simply the percentage correct on that trial. In dual task blocks the points were weighted 50:50 across the two tasks. A running total of points in that block was also presented at the bottom of the screen. Prior to starting this section of the experiment participants were informed that at the end of the session the points would be converted into an additional payment for participation, with a maximum of $£ 4$ or $\$ 5$ in addition to the base honorarium.

Analysis. Table 1 presents the titrated spans of younger and older adults for the two experiments reported here. As these data are not the focus of our present research questions, analysis of span is presented in the supplement.

The primary outcome measure for the analysis of memory task performance was serial recall accuracy. To be scored as correct a given letter had to be recalled in its correct serial position. For the processing task the main outcome was response accuracy in distinguishing correct and incorrect sums. Failures to respond within the given time window were classified as incorrect responses. Accuracy for the memory and processing tasks in the main experimental phase is analyzed via generalized (logistic) linear mixed effects models using the lme4 package (Bates, Maechler, Bolker, \& Walker, 2014). 
In each analysis we started with a full model with all main effects and interactions as fixed effects. Then we follow the same model selection procedure as in our previous work (Doherty et al., 2019; Rhodes et al., 2019). Specifically, we start at the highest order interaction (e.g., a three-way interaction) and remove this from the model. The reduced model is then compared to the full model via the Bayesian information criterion (BIC; Schwarz, 1978). If the reduced model produces a lower BIC the interaction is excluded and we proceed on to the next level of interactions (e.g., two-way). Each interaction at this level is removed to produce a model omitting this interaction and compared with the current full model. If $\mathrm{BIC}$ is lower without the interaction or effect, it is omitted. This continues through lower order interactions and main effects with the constraint that if an effect is subsumed by a higher interaction it is not removed. For example, if we retained a group $\times$ condition $\times$ site interaction we would not consider removing main effects or interactions involving these variables.

The BIC differences $(\Delta \mathrm{BIC})$ reported below are positive if the comparison favored removal of a particular effect and negative if the comparison favored retention. Raftery (1995 Table 6) provides guidance on interpreting absolute BIC differences: a difference of 0-2 is "weak", 2-6 provides "positive" evidence for or against the effect in question, 6-10 is "strong", and $>10$ is "very strong" evidence.

To speed up the model selection procedure we estimated the models with only a random participant intercept. Once the fixed effects had been selected, however, we introduced the full random effects structure to the winning model. This departs from our preregistered analysis plan (available at https://osf.io/9kt8x), which was otherwise identical but only included random intercepts; however, this move is conservative and will result in more appropriate estimates of uncertainty (standard errors) in the fixed effects (Barr, Levy, Scheepers, \& Tily, 2013). When the final model is simple enough we report the results in text, otherwise model coefficients are given in tables. 


\section{Results and Discussion}
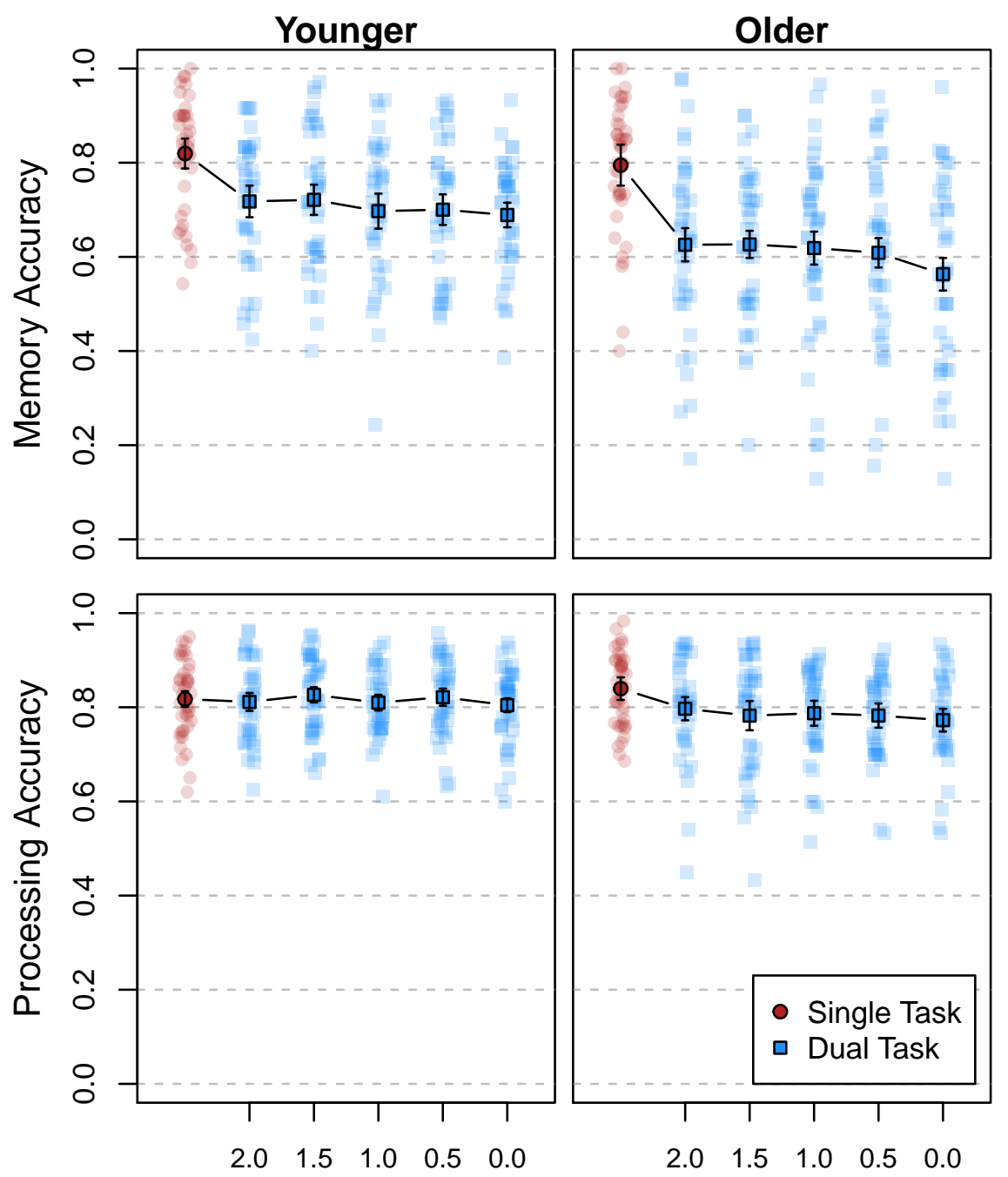

Post Sequence delay (s)

Figure 3. Experiment 1 accuracy for the memory and processing tasks performed individually (single task) and together (dual task). For dual task the delay following the to-be-remembered sequence of letters was varied.

Accuracy for the memory and processing task is depicted in Figure 3 for both the single task block and the blocks of dual task with different delays between the final letter and the onset of processing. For both accuracy measures the full model contained fixed effects of condition (single task and different dual task blocks), age group, and site. 
Condition was dummy coded such that single task was coded 0 and there was one variable for each dual task condition. Age group was effects coded such that younger $=-1$ and older $=1$. Site was coded such that UK $=1$ and US $=-1$. With this coding scheme, a condition by age group interaction could suggest that age differences in dual task costs are modulated by post-sequence delay.

Memory accuracy. The top panels of Figure 3 show that, while the two groups' memory accuracy is around $80 \%$ for single task, older adults' memory performance drops to a greater degree under dual task. Further, focusing within the dual task conditions, the post sequence delay appears to have little effect on accuracy. In the model comparison, BIC favored removal of the three-way interaction between age, condition, and site $(\Delta \mathrm{BIC}=16.6)$ as well as the two-way interactions (age by site: $\Delta \mathrm{BIC}=7.98$; condition by site: $\Delta \mathrm{BIC}=$ 1.97), including the crucial interaction between age and condition $(\Delta \mathrm{BIC}=28.2)$. The main effect of site was then removed $(\Delta \mathrm{BIC}=7.87)$. For the main effect of age the BIC difference was essentially zero $(\Delta \mathrm{BIC}=0.0728)$ so we decided to retain this in the final model. Finally, the main effect of condition was also retained $(\Delta \mathrm{BIC}=-379)$.

Assessing the final model coefficients we find that the intercept term, $b=1.67, \mathrm{SE}=$ $0.11, z=14.91, p<0.01$, suggests single task performance was approximately $84 \%$ correct (see Figure 3). The contrasts of the different post-sequence delay conditions were all of a similar magnitude $(2 \mathrm{~s}: b=-0.86, \mathrm{SE}=0.13, z=-6.52, p<0.01 ; 1.5 \mathrm{~s}: b=-0.89, \mathrm{SE}=$ $0.12, z=-7.43, p<0.01 ; 1 \mathrm{~s}: b=-0.96, \mathrm{SE}=0.13, z=-7.36, p<0.01 ; 0.5 \mathrm{~s}: b=-0.92, \mathrm{SE}$ $=0.14, z=-6.62, p<0.01 ; 0 \mathrm{~s}: b=-1.12, \mathrm{SE}=0.12, z=-9.58, p<0.01)$, suggesting that post sequence time had little effect on performance. Younger adults were more accurate than older adults, $b=-0.20, \mathrm{SE}=0.07, z=-2.86, p<0.01$.

To follow-up on this analysis we coded condition differently to compare conditions more directly. Specifically, we coded a contrast comparing the single task and $2.0 \mathrm{~s}$ postsequence interval conditions, comparing the 2 and $1.5 \mathrm{~s}$ conditions, and 3 additional contrasts 
comparing adjacent post-sequence interval conditions. With this "backwards difference" coding scheme we see that the single task and $2 \mathrm{~s}$ dual task condition differ significantly $(b=$ $-0.86, \mathrm{SE}=0.13, z=-6.52, p<0.01)$. Comparing the next four dual task conditions to one another we find no significant difference ( 2 vs 1.5: $b=-0.03, \mathrm{SE}=0.09, z=-0.33, p=0.74$; 1.5 vs $1: b=-0.07, \mathrm{SE}=0.11, z=-0.64, p=0.52 ; 1$ vs. $0.5: b=0.03, \mathrm{SE}=0.09, z=0.39$, $p=0.70)$, however, the contrast of the 0.5 interval and 0 interval conditions was significant $(b=-0.19, \mathrm{SE}=0.08, z=-2.36, p<0.05)$. Thus, there appears to be a benefit of giving some time between the presentation of the to-be-remembered sequence and the onset of processing but this benefit does not increase significantly with additional time.

Processing accuracy. For processing accuracy, shown in the bottom panels of Figure 3, there appears to be little overall dual task cost relative to single task and post-sequence delay does not appear to influence accuracy. In the analysis the three-way interaction was removed $(\Delta \mathrm{BIC}=28.9)$ followed by the two-way interactions (age by site: $\Delta \mathrm{BIC}=7.97 ;$ condition by site: $\Delta \mathrm{BIC}=9.98$; age by condition: $\Delta \mathrm{BIC}=8.45)$. Next the main effects of site $(\Delta \mathrm{BIC}=6.85)$ and age group $(\Delta \mathrm{BIC}=7.1)$ were removed leaving only a main effect of condition $(\triangle \mathrm{BIC}=-1.83)$. The intercept suggested around $85 \%$ accuracy in the single task block $(b=1.76, \mathrm{SE}=0.07, z=23.89, p<0.01)$ and, again, the contrasts suggested that the dual task cost did not vary systematically as a function of post sequence interval $(2 \mathrm{~s}: b=-0.23, \mathrm{SE}=0.08, z=-2.81, p<0.01 ; 1.5 \mathrm{~s}: b=-0.16, \mathrm{SE}=0.09, z=$ $-1.81, p=0.07 ; 1 \mathrm{~s}: b=-0.28, \mathrm{SE}=0.09, z=-3.26, p<0.01 ; 0.5 \mathrm{~s}: b=-0.26, \mathrm{SE}=0.08, z$ $=-3.23, p<0.01 ; 0 \mathrm{~s}: b=-0.34, \mathrm{SE}=0.08, z=-4.34, p<0.01)$.

As in the analysis of memory accuracy, we followed up this analysis by differently coding condition to directly compare them. The contrast between single task and the $2 \mathrm{~s}$ dual task condition suggested that there was a drop in processing accuracy between single task and dual task $(b=-0.23, \mathrm{SE}=0.08, z=-2.81, p<0.01)$. The remaining contrasts between dual task conditions were not significant (2 vs 1.5: $b=0.07, \mathrm{SE}=0.06, z=1.01, p$ 
$=0.31 ; 1.5$ vs $1: b=-0.12, \mathrm{SE}=0.07, z=-1.76, p=0.08 ; 1$ vs. $0.5: b=0.02, \mathrm{SE}=0.07, z$ $=0.31, p=0.76 ; 0.5$ vs. $0: b=-0.08, \mathrm{SE}=0.06, z=-1.26, p=0.21)$.

In the analysis of both memory and processing accuracy the condition by age group interaction was omitted from the final model. In these analyses this effect was coded by 5 coefficients contrasting the single task condition and the dual task conditions with different post-sequence intervals. A more focused test of age differences in dual task costs would simply contrast single and dual task conditions (i.e., 1 coefficient). In the supplementary material we present follow up analyses with the single vs. dual task contrast. In this case the condition by age group interaction was retained for both memory accuracy (replicating Rhodes et al., 2019) and processing accuracy.

Processing reaction times. Figure 4 shows reaction time to the first four processing items by condition and age group. We analyzed RTs with a linear mixed effects model with a contrast for first processing item and age group. Condition was backwards difference coded such that single task was compared to a postsequence delay of $2 \mathrm{~s}, 2 \mathrm{~s}$ was compared to $1.5 \mathrm{~s}$, and so on for each comparison of adjacent conditions. In this analysis BIC clearly favored removal of the three-way interaction between age-group, processing item (first vs. rest), and condition ( $\triangle \mathrm{BIC}=25.1)$, suggesting that post-sequence time did not modulate age differences in first processing times. Therefore, we did a follow-up analysis where condition was simply coded as single or dual task. In this case the three-way interaction was retained $(\Delta \mathrm{BIC}=-7.02)$, consistent with the observation from our previous data set that older adults exhibit particularly slow first processing times under dual task conditions. These analyses are presented in full in the supplement.

In sum, contrary to our expectation, providing more time between list presentation and the onset of the processing task had no clear effect on the slowing of first reaction times under dual task conditions. Further, older adults still exhibited disproportionate slowing for the first processing event under dual task conditions. 


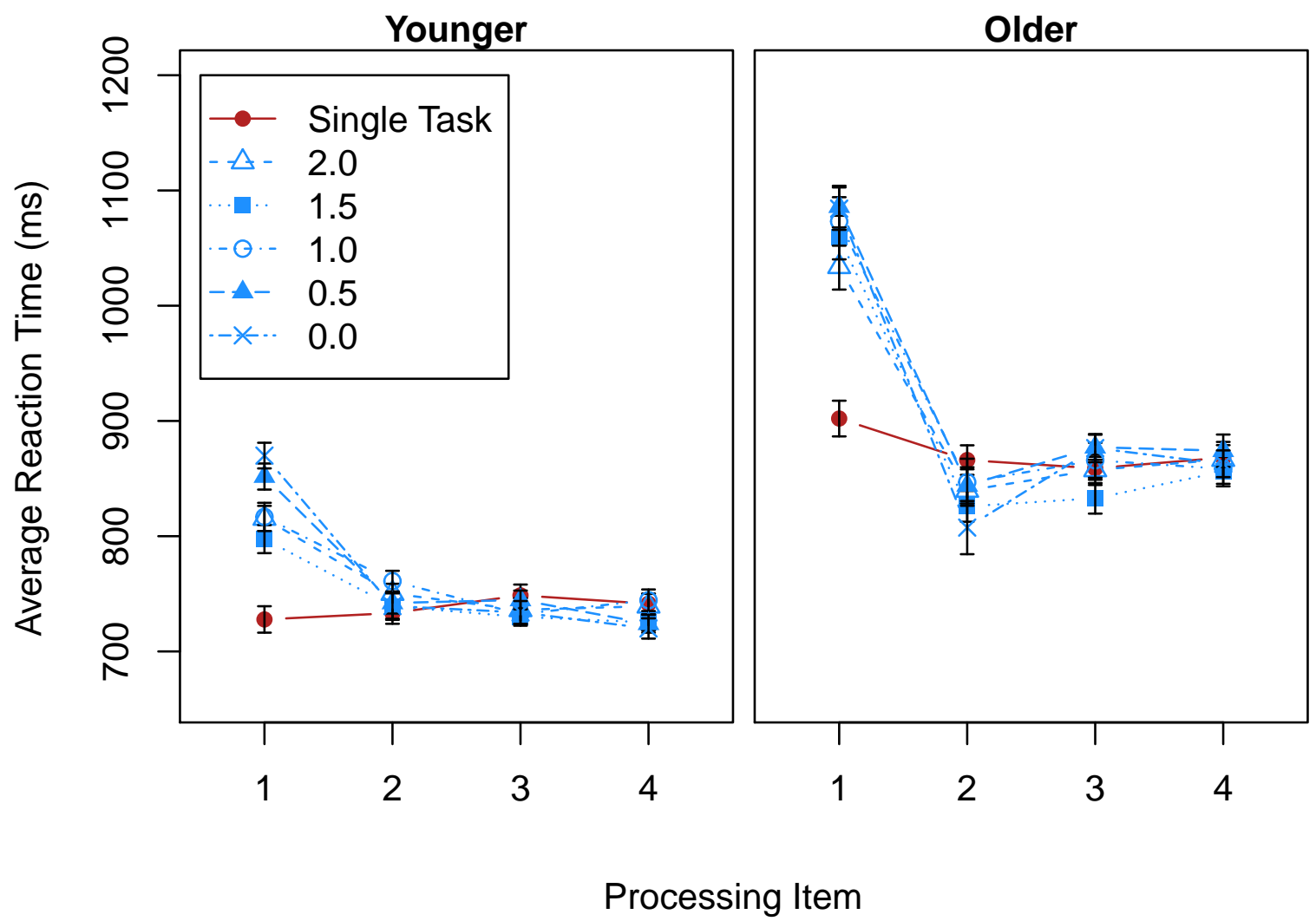

Figure 4. Processing reaction times for the first four items in Experiment 1

\section{Experiment 2: Pace of list presentation}

Experiment 1 showed that varying the amount of time between list presentation and the onset of the processing task did not modulate age differences in performance. This suggests that the greater dual task cost seen in older adults' recall performance is not alleviated by allowing more time to encode the entire list before switching to the processing task. In Experiment 2 we explored another aspect of the encoding period that may influence performance, specifically the pace of list presentation.

A large body of work now shows that encoding information into working memory is not an all or none process. Rather, individual representations appear to consolidate or strengthen over time following presentation (Vergauwe, Ricker, Langerock, \& Cowan, 2019). Estimates of the amount of time needed to consolidate representations in working memory 
vary due to a range of experimental factors (see Ricker, Nieuwenstein, Bayliss, \& Barrouillet, 2018 for a review). A typical finding is that processing is slowed (Jolicour \& Dell'Acqua, 1998; Stevanovski \& Jolicoeur, 2007) or recall performance is disrupted (Nieuwenstein \& Wyble, 2014; Ricker \& Hardman, 2017) when the onset of the to-be-remembered information and the processing task is separated by less than $1 \mathrm{~s}$.

However, as noted by Ricker et al. (2018), there are situations where individual representations may continue to strengthen beyond this time-frame. Particularly relevant data come from De Schrijver and Barrouillet (2017) who varied the amount of time between to-be-recalled letters and bursts of processing (odd/even judgements) that would appear between letters. Each letter was presented for $500 \mathrm{~ms}$ and followed by a blank period of between 0 and $5 \mathrm{~s}$. Improvement in performance slowed down over the range of times used but still showed a tendency to improve following 1 s (see also Bayliss, Bogdanovs, \& Jarrold, 2015). In a simpler immediate serial recall task, Tan and Ward (2008) considered presentation rates of $1,2.5$, or $5 \mathrm{~s}$ per item and saw a recall benefit with each increase in study time. Thus, it seems possible that varying the time allowed to strengthen each individual item would modulate the susceptibility of representations to a distracting concurrent task presented during retention (see Barrouillet, Plancher, Guida, \& Camos, 2013 for evidence supporting this).

There is also reason to suspect that a beneficial effect of lengthening time to strengthen individual representations (or a detrimental effect of reducing this time) would be stronger for older adults. In particular, it has been shown that the duration of the attentional blink increases considerably with age (Georgiou-Karistianis et al., 2007; Jain \& Kar, 2014; Lahar, Isaak, \& McArthur, 2001; Maciokas \& Crognale, 2003). The attentional blink refers to the finding that identification of a target stimulus within a stream of stimuli is impaired when it is closely preceded by another target. This is thought to reflect the selection and consolidation of the first target into working memory for later report (e.g., 
Chun \& Potter, 1995) and recent studies have suggested that the consolidation seen in working memory paradigms functions much like the attentional blink (Nieuwenstein \& Wyble, 2014; Ricker \& Hardman, 2017). Our finding that older adults exhibited a greater concurrence cost in their recall following distraction may reflect slower and/or less efficient consolidation of individual items into working memory. If this is the case, we may expect older participants to benefit from a slower pace of presentation of to-be-remembered items to a greater degree than younger adults (who may have almost fully consolidated letters at the 1 s per item pace we used). Simultaneously, we would also expect that reducing the time in-between memory items would disproportionately harm older adults, especially under dual task conditions. In our previous experiment individual letters were presented for $250 \mathrm{~ms}$ and separated by a $750 \mathrm{~ms}$ interval. In this experiment we varied the duration of this interval to either speed up or slow down the pace of list presentation.

\section{Method}

Participants. Fifty four older adults (aged 65-82; 27 each site) and 54 younger adults (aged 18-30; 27 each site) who had not participated in our previous experiments were recruited from the same sources as Experiment 1. More detail on these participants can be found in Table 1 and no participants were excluded (using the same criteria as Experiment 1).

Stimuli and Procedure. In this experiment, prior to completing the titration and main experimental phase, participants completed both simple and choice reaction time tasks provided by Deary, Liewald, and Nissan (2011). This measure was included to get an independent measure of processing speed to relate to performance in the main task (these results are presented in the supplement).

In Experiment 2 the post-sequence delay was set to $1 \mathrm{~s}$ and there was no delay 
following the final processing item (or placeholder). Rather, what was varied during the main experimental phase was the interval between letters presented for the memory task. Each letter was presented for $250 \mathrm{~ms}$ and followed by a $250 \mathrm{~ms}, 750 \mathrm{~ms}$, or $1250 \mathrm{~ms}$ ISI (see Figure 1). The $750 \mathrm{~ms}$ ISI was used in Experiment 1 and was used during the titration phase of this experiment.

During the main experimental phase of Experiment 2 participants completed 7 blocks of 2 practice trials and 8 experimental trials. There were three single task memory blocks and three dual task blocks (one for each ISI) as well as one single task processing block. The three different tasks (single task memory, single task processing, and dual task) were completed in a counterbalanced order. For example, a participant may complete all single task memory blocks, then single task processing, and end the session with the three dual task blocks. Further, the order of the three ISI conditions was counterbalanced according to a Latin square with the restriction that participants completed the same order for both single task memory and dual task. As in Experiment 1, participants received feedback following each trial in the main phase and were able to earn the same monetary reward. The titration procedure was the same as Experiment 1.

\section{Results and Discussion}

Memory accuracy. The top panels of Figure 5 show recall accuracy as a function of ISI between letters in the memory task. The main aspect of these data to note is that accuracy appears to increase with greater separation of the letters and the degree of this

improvement looks similar across conditions and age groups. Once again, the main difference between the age groups is in memory performance in the dual task blocks.

In the analysis the full model contained four fixed effects and their interactions. Condition was coded such that single task was -1 and dual task was 1 and site was coded as 


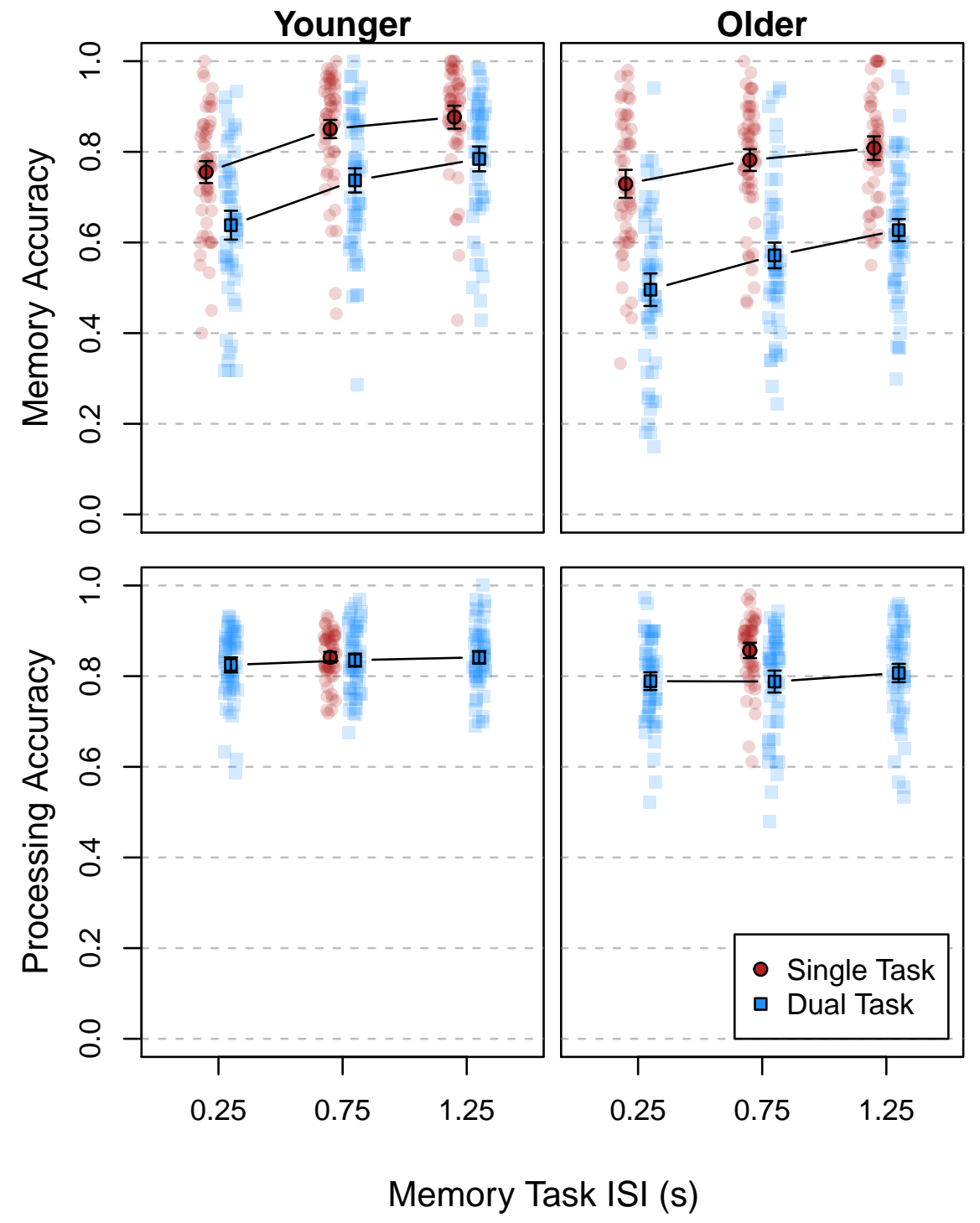

Figure 5. Experiment 2 accuracy for the memory and processing tasks. The inter-stimulus interval between letters in the memory task was varied under both single task and dual task conditions. 
in Experiment $1(\mathrm{UK}=1$, US $=-1)$. For the factor of ISI the $750 \mathrm{~ms}$ was set as the reference leading to two contrasts, one for $250 \mathrm{~ms}$ and another for $1250 \mathrm{~ms}$.

BIC supported removal of the condition by ISI by group by site interaction $(\Delta \mathrm{BIC}=$ 8.36). Next we considered removal of the three-way interactions. The ISI by group by site interaction was retained $(\Delta \mathrm{BIC}=-12.2)$, whereas the other interactions could be removed (condition $\times$ ISI $\times$ site: $\Delta \mathrm{BIC}=16.5$; condition $\times$ group $\times$ site: $\Delta \mathrm{BIC}=6.16$ ). Crucially, this included the condition $\times$ ISI $\times$ group interaction $(\Delta \mathrm{BIC}=15.3)$, suggesting that group differences in performance under single and dual task conditions was not differentially modulated by the manipulation of ISI.

At the next stage the two-way interactions not subsumed in the retained three-way interactions were tested. The condition by group interaction was retained $(\Delta \mathrm{BIC}=-41.4)$, but the condition by site $(\Delta \mathrm{BIC}=8.19)$ and condition by ISI $(\Delta \mathrm{BIC}=14.3)$ interactions were removed. This resulted in the final model presented in Table 2.

The significant age by ISI 250 contrast suggests that age differences in accuracy are smaller with the shortest ISI. However, this is qualified by the three way interaction with site, which suggests that this is primarily driven by the UK site. This interaction is plotted and discussed in more detail in the supplementary material. Importantly, the condition by group interaction shows that age differences are larger under dual task versus single task (again, replicating Rhodes et al., 2019).

The omission of the group by condition by ISI interaction (see above) suggests that manipulating the time available between to-be-remembered letters did not modulate the size of this age-related dual task deficit in the memory task. Nevertheless, Table 2 does suggest that ISI influenced recall performance overall with significantly better performance with a $1250 \mathrm{~ms}$ ISI (see the "ISI long" contrast) and significantly poorer accuracy with a $250 \mathrm{~ms}$ ISI (see the "ISI short" contrast). This improvement in performance with a slower pace of 
presentation can also clearly be seen in Figure 5 and is in line with the findings of Tan and Ward (2008), although in their experiments the pace of list presentation was changed by varying how long each to-be-remembered item was presented.

Table 2

Final model for memory accuracy in Experiment 2.

\begin{tabular}{lrrrr}
\hline Parameter & $b$ & Std. Err & $z$ & $p$ \\
\hline Intercept & 1.17 & 0.064 & 18.414 & $<0.01$ \\
Condition & -0.474 & 0.034 & -13.874 & $<0.01$ \\
ISI short & -0.38 & 0.037 & -10.126 & $<0.01$ \\
ISI long & 0.313 & 0.043 & 7.266 & $<0.01$ \\
Age group & -0.298 & 0.063 & -4.712 & $<0.01$ \\
Site & 0.04 & 0.061 & 0.654 & $=0.51$ \\
Condition $\times$ Group & -0.101 & 0.034 & -3.003 & $<0.01$ \\
ISI $250 \times$ Group & 0.099 & 0.037 & 2.695 & $<0.01$ \\
ISI $1250 \times$ Group & -0.077 & 0.042 & -1.837 & $=0.07$ \\
ISI $250 \times$ Site & 0.01 & 0.035 & 0.271 & $=0.79$ \\
ISI $1250 \times$ Site & 0.002 & 0.04 & 0.059 & $=0.95$ \\
Group $\times$ Site & -0.149 & 0.063 & -2.351 & $<0.05$ \\
ISI $250 \times$ Group $\times$ Site & 0.119 & 0.036 & 3.28 & $<0.01$ \\
ISI $1250 \times$ Group $\times$ Site & -0.075 & 0.041 & -1.834 & $=0.07$ \\
\hline Note: Con & &
\end{tabular}

Note: Condition was coded such that single task $=1$, dual task $=-1$. For ISI $750 \mathrm{~ms}$ was made the reference level (coded -1$)$ and the 250 and 1250 ISI condition each have a contrast. Age group was coded such that younger $=-1$, older $=1$. Site was coded such that $\mathrm{US}=-1, \mathrm{UK}=1$. 
Processing accuracy. The bottom panels of Figure 5 show processing accuracy. The ISI between letters in the memory task appears to have had little effect on processing accuracy.

For the analysis of processing accuracy we focused on data from the dual task blocks, as these were associated with a particular between-letter ISI in the memory task. There was evidence against the group $\times$ ISI $\times$ site interaction $(\Delta \mathrm{BIC}=14.4)$. BIC also favored removal of the group by site $(\Delta \mathrm{BIC}=7.7)$, ISI by site $(\Delta \mathrm{BIC}=15.4)$, and ISI by group $(\Delta \mathrm{BIC}=$ 12.6) interactions. Finally, each of the main effects could be removed (site: $\Delta \mathrm{BIC}=6.47$; ISI: $\Delta \mathrm{BIC}=6.79$; group: $\Delta \mathrm{BIC}=2.42)$. This left the intercept only, $b=1.64, \mathrm{SE}=0.05, z$ $=31.15, p<0.01$. The reason for this can be seen in Figure 5, where average performance under dual task conditions remains close to $80 \%$ for both groups. Processing reaction times were of less interest in this experiment and are therefore presented in the supplement.

In summary, age differences in memory performance were larger under dual task versus single task. While manipulating the time available between to-be-remembered letters significantly improved recall performance overall, it did not modulate the size of this age-related dual task deficit. Converging evidence comes from the analysis of individual differences in single and choice reaction time on the Deary-Liewald task showing that these independent measures of processing speed do little to account for age differences in dual task performance (see supplement).

While younger and older adults exhibited roughly equivalent benefit in memory accuracy with increasing ISI between to-be-remembered letters, it could be argued that younger participants benefited more from this manipulation as they (on average) saw longer lists and more processing events, due to the titration procedure. Thus, it could be argued that the ISI manipulation merely carried forward age-related differences in processing speed, with the faster younger adults benefiting more. However, we note that recall performance in both single and dual task conditions improved at approximately the same rate for younger 
and older adults. Consequently, even if younger adults did have to benefit more from extra time to produce a similar accuracy increase to older adults, this did not modulate the relative size of these two groups' dual task cost. Therefore, we suggest that baseline (i.e., single task) performance differences between younger and older adults in their memory performance can be explained, to some degree, by differences in speed of encoding (see the supplement for support for this using the Deary-Liewald RT measures and memory span), and can be modulated by allowing more time to consolidate individual items. This extra time, however, does not appear to modulate the cost to performance due to distraction.

\section{General Discussion}

There have been mixed reports in the literature as to whether there is an age-related increase in the magnitude of working memory dual task costs. Specifically, whether concurrent storage and processing demands result in larger age differences in performance relative to when these demands are presented individually. It has been suggested that there are circumstances under which there is no age-related dual task cost when the demand of the tasks is titrated or adjusted to account for individual differences in baseline task performance before the two are combined (e.g., Anderson et al., 2011; Baddeley et al., 1986; Logie et al., 2004, 2015). Recently, we tested the generalizability of this proposal in a large group of participants aged 18 to 81 and found that age was associated with a larger drop in memory task performance with a concurrent processing load, even after titration of task difficulty (Rhodes et al., 2019). The range of tasks used in the literature make pinning down the source of discrepancies (i.e., whether an age-related dual task cost is found or not) in findings difficult and there is a substantial amount of variability in effect sizes that is left to explain (Jaroslawska \& Rhodes, 2019). Thus, to follow up on our previous findings, in these experiments we chose to stick with the tasks that had yielded a clear age effect and manipulate the timing of the encoding period in ways motivated by the wider literature on 
working memory. In doing so we wanted to identify factors that may modulate the age-related cost for memory performance under dual task. The two experiments reported here also served to replicate a main finding from Rhodes et al. (2019) that, with the task combinations that we have used, age is associated with an increase in the magnitude of dual task costs for memory performance.

Neither of the encoding factors we identified - the delay between list presentation and the onset of processing or the pace of the memory list - modulated the size of the age related dual task cost for serial recall under concurrent processing. In each case BIC model comparison provided evidence against such modulation. While such null findings do not get us closer to understanding the source of this age difference they do rule out several factors as possible drivers of this effect, at least within the range of settings used in the current experiments. In Experiment 1 we were motivated by findings of delayed reaction times for the first processing event during the retention interval, which may reflect the need to switch between the two demands (e.g., Vergauwe et al., 2014). Reanalysis of the data from Rhodes et al. (2019) suggested that the degree of slowing for the first processing event was greater for older participants, indicating that they may need additional time to finish encoding the to-be-remembered list and switch to engage with the processing task. However, providing extra time following the presentation of the list before the onset of the processing task did not influence age differences in recall performance under dual task. Thus, slower or less complete encoding of the list prior to switching to processing does not appear to drive differences between the age groups.

Experiment 2 showed that both groups benefited from a slower rate of presentation of the memory list. Increasing the ISI between to-be-remembered letters improved performance under both single and dual task conditions and, importantly, it did not modulate the gap between young and old. Thus, while a slower rate of presentation may help both groups better encode and consolidate information, this does not appear to protect from the 
disruptive effects of the processing task presented during the retention interval.

As outlined in the introduction, age-related slowing was a major motivation for manipulating temporal factors in the present task (e.g., Cerella, 1985; Deary et al., 2010). Our findings suggest that, while there is shared age-related variance between processing speed and working memory performance (Salthouse, 1991, 2015; Salthouse \& Babcock, 1991), age-differences in performance under dual task conditions are not alleviated by allowing more time for encoding of to-be-remembered information (specifically, letters in this case). Indeed, slower speed of processing and poorer recall following distraction may both reflect, to some degree, age-related difficulties in dealing with distraction (see Lustig, Hasher, \& Tonev, 2006). We return to the topic of age differences in susceptibility to distraction and interference below.

The consistent dual task cost for letter recall when combined with concurrent arithmetic processing in both younger and older adults (Doherty et al., 2019; Rhodes et al., 2019) clearly shows that this processing task disrupts maintenance of letters in working memory. This disruption could be due to the prevention of rehearsal, which could be subvocal in nature (e.g., Jarrold et al., 2011) or reflect the action of a more general attentional resource that serves to "refresh" representations (e.g., Camos, Lagner, \& Barrouillet, 2009). In addition, it may reflect a degree of retroactive interference caused by encoding the processing problems into working memory in order to solve them (e.g., Lewandowsky, Geiger, \& Oberauer, 2008). A common assumption of many working memory models is that information displaced from active maintenance can be reconstructed via effortful search through "secondary" (more long-term) memory (Atkinson \& Shiffrin, 1968; Jarrold, Tam, Baddeley, \& Harvey, 2010; Unsworth \& Engle, 2007). This may account for some of the age differences we find here (see the supplement for additional tests of other factors).

In the literature on long-term memory there is evidence that search and retrieval from 
secondary memory appears to be particularly difficult for older adults (e.g., Danckert \& Craik, 2013; Healey \& Kahana, 2016; Rhodes, Greene, \& Naveh-Benjamin, 2019). Consistent with this, in working memory span tasks older adults appear to be more susceptible to effects of proactive interference (Lustig, May, \& Hasher, 2001; May, Hasher, \& Kane, 1999), suggesting that they are less able to effectively constrain search to items that occurred on the most recent trial. This would result in poorer recall of both order and individual letters (item memory), consistent with analyses presented in the supplement showing that memory for the letters themselves, irrespective of order, also shows a clear age-related dual task cost. Thus, age differences in search and retrieval from secondary memory following distraction could explain the consistent dual task cost for memory performance seen here. Further, a retrieval source is consistent with the lack of effect of the temporal manipulations implemented here at encoding. An additional, not mutually exclusive, source of age effects could be a greater susceptibility to distraction and retroactive interference from the processing task (e.g. Healey, Hasher, \& Campbell, 2013; Hedden \& Park, 2003).

There may be some processing tasks that produce very minimal disruptive effects. For example, several studies using a visuo-motor tracking task combined with serial recall have reported no age related dual task costs (Baddeley, Baddeley, Bucks, \& Wilcock, 2001;

Baddeley et al., 1986; Foley, Kaschel, Logie, \& Della Sala, 2011; Logie et al., 2004). In the wider dual tasking literature there is work suggesting that age differences are reduced when "ideomotor-compatible" tasks are used (e.g., Hartley, Seaman, \& Maquestiaux, 2015). These are tasks where "a stimulus closely resembles the sensory feedback after the response to the stimulus is made" for example "in which a joystick is moved in the direction indicated by an arrow" (see Hartley et al., 2015, p. 38). There are other aspects of the present work that differ from previous studies finding no significant age-related dual task cost, therefore, a systematic comparison of different processing tasks should be a focus of future research (e.g., Jaroslawska et al., Under review). 


\section{Conclusion}

The present study aimed to explore differences in working memory dual task performance between younger and older adults. Our previous work had suggested that, even under conditions where task demand has been titrated to individual ability, older participants exhibit a more substantial drop in serial recall of letters when this task is combined with a concurrent arithmetic processing task in the retention interval (Rhodes et al., 2019). The results presented here serve to replicate the finding that, with these tasks, older adults' recall is disrupted to a greater extent by concurrent processing relative to younger adults. Further, our results make clear that manipulating the time available for encoding or consolidating memory traces before switching to a processing demand does not ameliorate the disadvantage shown by older participants, even when the demands of the two tasks are adjusted to the individual ability of each participant. The broader literature suggests that different processing demands may produce different results. We speculate that differences between different forms of processing will come down to the extent to which they disrupt active maintenance in working memory, requiring search and retrieval from secondary memory.

\section{References}

Anderson, M., Bucks, R. S., Bayliss, D. M., \& Sala, S. della. (2011). Effect of age on dual-task performance in children and adults. Memory and Cognition, 39(7), 1241-1252. https://doi.org/10.3758/s13421-011-0099-7

Atkinson, R. C., \& Shiffrin, R. M. (1968). Human memory: A proposed system and its control processes. In Psychology of learning and motivation (Vol. 2, pp. 89-195). Elsevier.

Aust, F., \& Barth, M. (2020). papaja: Create APA manuscripts with $R$ Markdown. 
Retrieved from https://github.com/crsh/papaja

Baddeley, A. D. (2007). Working memory, thought, and action. Oxford University Press.

Baddeley, A. D., \& Hitch, G. J. (1974). Working memory. In G. A. Bower (Ed.), Recent advances in learning and motivation (Vol. 8, pp. 47-90). Academic Press.

Baddeley, A. D., Baddeley, H. A., Bucks, R. S., \& Wilcock, G. K. (2001). Attentional control in Alzheimer's disease. Brain, 124(8), 1492-1508.

https://doi.org/10.1093/brain/124.8.1492

Baddeley, A. D., Logie, R. H., Bressi, S., Della Sala, S., \& Spinnler, H. (1986). Dementia and working memory. The Quarterly Journal of Experimental Psychology, 38(4), 603-618. https://doi.org/10.1080/14640748608401616

Barr, D. J., Levy, R., Scheepers, C., \& Tily, H. J. (2013). Random effects structure for confirmatory hypothesis testing: Keep it maximal. Journal of Memory and Language, 68(3), 255-278. https://doi.org/10.1016/j.jml.2012.11.001

Barrouillet, P., \& Camos, V. (2015). Working memory: loss and reconstruction (Vol. 52, pp. 52-4496-52-4496). Psychology Press. https://doi.org/10.5860/choice.189287

Barrouillet, P., Plancher, G., Guida, A., \& Camos, V. (2013). Forgetting at short term: When do event-based interference and temporal factors have an effect? Acta Psychologica, 142(2), 155-167. https://doi.org/10.1016/j.actpsy.2012.12.003

Bates, D., Maechler, M., Bolker, B., \& Walker, S. (2014). lme4: Linear mixed-effects models using Eigen and S4. Retrieved from http://cran.r-project.org/package=lme4

Bayliss, D. M., Bogdanovs, J., \& Jarrold, C. (2015). Consolidating working memory: Distinguishing the effects of consolidation, rehearsal and attentional refreshing in a working memory span task. Journal of Memory and Language, 81, 34-50. 
https://doi.org/10.1016/j.jml.2014.12.004

Belletier, C., Doherty, J. M., Jaroslawska, A. J., Rhodes, S., Cowan, N., Naveh-Benjamin, M., ... Logie, R. H. (Under review). Strategic Adaptations to Dual-Tasking in Verbal Working Memory.

Bier, B., Lecavalier, N. C., Malenfant, D., Peretz, I., \& Belleville, S. (2017). Effect of Age on Attentional Control in Dual-Tasking. Experimental Aging Research, 43(2), 161-177. https://doi.org/10.1080/0361073X.2017.1276377

Bopp, K. L., \& Verhaeghen, P. (2005). Aging and verbal memory span: A meta-analysis. Journals of Gerontology - Series B Psychological Sciences and Social Sciences, 60(5), P223_-P233. https://doi.org/10.1093/geronb/60.5.P223

Camos, V., Lagner, P., \& Barrouillet, P. (2009). Two maintenance mechanisms of verbal information in working memory. Journal of Memory and Language, 61(3), 457-469. https://doi.org/10.1016/j.jml.2009.06.002

Camos, V., Mora, G., Oftinger, A. L., Elsig, S. M., Schneider, P., \& Vergauwe, E. (2019). Does semantic long-term memory impact refreshing in verbal working memory? Journal of Experimental Psychology: Learning Memory and Cognition, 45(9), 1664-1682. https://doi.org/10.1037/xlm0000657

Cerella, J. (1985). Information Processing Rates in the Elderly. Psychological Bulletin, 98(1), 67-83. https://doi.org/10.1037/0033-2909.98.1.67

Chen, Z., \& Cowan, N. (2009). How verbal memory loads consume attention. Memory and Cognition, 37(6), 829-836. https://doi.org/10.3758/MC.37.6.829

Chevalère, J., Lemaire, P., \& Camos, V. (2020). Age-related changes in verbal working memory strategies. Experimental Aging Research, 46(2), 93-127. 
https://doi.org/10.1080/0361073X.2020.1716152

Chun, M. M., \& Potter, M. C. (1995). A Two-Stage Model for Multiple Target Detection in Rapid Serial Visual Presentation. Journal of Experimental Psychology: Human Perception and Performance, 21(1), 109-127. https://doi.org/10.1037/0096-1523.21.1.109

Cowan, N. (2010). The magical mystery four: How is working memory capacity limited, and why? Current Directions in Psychological Science, 19(1), 51-57. https://doi.org/10.1177/0963721409359277

Cowan, N. (2017). The many faces of working memory and short-term storage. Psychonomic Bulletin and Review, 24(4), 1158-1170. https://doi.org/10.3758/s13423-016-1191-6

Cowan, N., Belletier, C., Doherty, J. M., Jaroslawska, A. J., Rhodes, S., Forsberg, A., ... Logie, R. H. (2020). How Do Scientific Views Change? Notes From an Extended Adversarial Collaboration. Perspectives on Psychological Science, 15(4), 1011-1025. https://doi.org/10.1177/1745691620906415

Cowan, N., Saults, J. S., \& Blume, C. L. (2014). Central and peripheral components of working memory storage. Journal of Experimental Psychology: General, 143(5), 1806-1836. https://doi.org/10.1037/a0036814

Danckert, S. L., \& Craik, F. I. (2013). Does aging affect recall more than recognition memory? Psychology and Aging, 28(4), 902-909. https://doi.org/10.1037/a0033263

De Schrijver, S., \& Barrouillet, P. (2017). Consolidation and restoration of memory traces in working memory. Psychonomic Bulletin and Review, 24(5), 1651-1657. https://doi.org/10.3758/s13423-017-1226-7

Deary, I. J., Johnson, W., \& Starr, J. M. (2010). Are Processing Speed Tasks Biomarkers of 
Cognitive Aging? Psychology and Aging, 25(1), 219-228.

https://doi.org/10.1037/a0017750

Deary, I. J., Liewald, D., \& Nissan, J. (2011). A free, easy-to-use, computer-based simple and four-choice reaction time programme: the Deary-Liewald reaction time task. Behavior Research Methods, 43(1), 258-268. https://doi.org/10.3758/s13428-010-0024-1

Doherty, J. M., \& Logie, R. H. (2016). Resource-sharing in multiple-component working memory. Memory \& Cognition, 44(8), 1157-1167. https://doi.org/10.3758/s13421-016-0626-7

Doherty, J. M., Belletier, C., Rhodes, S., Jaroslawska, A. J., Barrouillet, P., Camos, V., ... Logie, R. H. (2019). Dual-Task Costs in Working Memory: An Adversarial Collaboration. Journal of Experimental Psychology: Learning Memory and Cognition, 45(9), 1529. https://doi.org/10.1037/xlm0000668

Fanuel, L., Plancher, G., Monsaingeon, N., Tillmann, B., \& Portrat, S. (2018). Temporal dynamics of maintenance in young and old adults. Annals of the New York Academy of Sciences, 1424(1), 137-148. https://doi.org/10.1111/nyas.13640

Foley, J. A., Kaschel, R., Logie, R. H., \& Della Sala, S. (2011). Dual-task performance in Alzheimer's disease, mild cognitive impairment, and normal ageing. Archives of Clinical Neuropsychology, 26(4), 340-348. https://doi.org/10.1093/arclin/acr032

Georgiou-Karistianis, N., Tang, J., Vardy, Y., Sheppard, D., Evans, N., Wilson, M., ... Bradshaw, J. (2007). Progressive age-related changes in the attentional blink paradigm. Aging, Neuropsychology, and Cognition, 14(3), 213-226. https://doi.org/10.1080/13825580500320681

Hartley, A. A., Seaman, B., \& Maquestiaux, F. (2015). Ideomotor-compatible tasks partially escape dual-task interference in both young and elderly adults. Psychology and Aging, 
30 (1), 36-45. https://doi.org/10.1037/pag0000015

Healey, M. K., \& Kahana, M. J. (2016). A four-component model of age-related memory change. Psychological Review, 123(1), 23-69. https://doi.org/10.1037/rev0000015

Healey, M. K., Hasher, L., \& Campbell, K. L. (2013). The role of suppression in resolving interference: Evidence for an age-related deficit. Psychology and Aging, 28(3), 721. https://doi.org/10.1037/a0033003

Hedden, T., \& Park, D. C. (2003). Contributions of Source and Inhibitory Mechanisms to Age-Related Retroactive Interference in Verbal Working Memory. Journal of Experimental Psychology: General, 132(1), 93-112. https://doi.org/10.1037/0096-3445.132.1.93

Jain, S., \& Kar, B. R. (2014). Effect of Cognitive Aging on Working Memory Consolidation. Psychological Studies, 59(4), 383-393. https://doi.org/10.1007/s12646-014-0276-4

Jaroslawska, A. J., \& Rhodes, S. (2019). Adult age differences in the effects of processing on storage in working memory: A meta-analysis. Psychology and Aging, 34(4), 512-530. https://doi.org/10.1037/pag0000358

Jaroslawska, A. J., Rhodes, S., Belletier, C., Doherty, J. M., Cowan, N., Naveh-Benjamin, M., ... Logie, R. H. (Under review). What Affects the Magnitude of Age-Related Dual-Task Costs in Working Memory? The Role of Stimulus Domain and Access to Semantic Representations.

Jarrold, C., Tam, H., Baddeley, A. D., \& Harvey, C. E. (2010). The nature and position of processing determines why forgetting occurs in working memory tasks. Psychonomic Bulletin and Review, 17(6), 772-777. https://doi.org/10.3758/PBR.17.6.772

Jarrold, C., Tam, H., Baddeley, A. D., \& Harvey, C. E. (2011). How Does Processing Affect 
Storage in Working Memory Tasks? Evidence for Both Domain-General and Domain-Specific Effects. Journal of Experimental Psychology: Learning Memory and Cognition, 37(3), 688-705. https://doi.org/10.1037/a0022527

Jolicœur, P., \& Dell'Acqua, R. (1998). The demonstration of short-term consolidation. Cognitive Psychology, 36(2), 138-202. https://doi.org/10.1006/cogp.1998.0684

Lahar, C. J., Isaak, M. I., \& McArthur, A. D. (2001). Age differences in the magnitude of the attentional blink. Aging, Neuropsychology, and Cognition, 8(2), 149-159. https://doi.org/10.1076/anec.8.2.149.842

Lewandowsky, S., Geiger, S. M., \& Oberauer, K. (2008). Interference-based forgetting in verbal short-term memory. Journal of Memory and Language, 59(2), 200-222. https://doi.org/10.1016/j.jml.2008.04.004

Logie, R. H. (1995). Visuo-spatial working memory. Hove, UK: Lawrence Erlbaum.

Logie, R. H. (2011). The functional organization and capacity limits of working memory. Current Directions in Psychological Science, 20(4), 240-245. https://doi.org/10.1177/0963721411415340

Logie, R. H. (2016). Retiring the central executive. Quarterly Journal of Experimental Psychology, 69(10), 2093-2109. https://doi.org/10.1080/17470218.2015.1136657

Logie, R. H. (2018). Human Cognition: Common Principles and Individual Variation. Journal of Applied Research in Memory and Cognition, 7(4), 471-486. https://doi.org/10.1016/j.jarmac.2018.08.001

Logie, R. H., Camos, V., \& Cowan, N. (Eds.). (2021). Working memory: State of the science. Oxford University Press.

Logie, R. H., Cocchini, G., Della Sala, S., \& Baddeley, A. D. (2004). Is there a specific 
executive capacity for dual task coordination? Evidence from Alzheimer's disease. Neuropsychology, 18(3), 504-513. https://doi.org/10.1037/0894-4105.18.3.504

Logie, R. H., Horne, M. J., \& Pettit, L. D. (2015). When cognitive performance does not decline across the lifespan. In Working memory and ageing (pp. 37-63). Psychology Press.

Logie, R. H., Sala, S. D., Laiacona, M., Chalmers, P., \& Wynn, V. (1996). Group aggregates and individual reliability: The case of verbal short-term memory. Memory and Cognition, 24(3), 305-321. https://doi.org/10.3758/BF03213295

Lustig, C., Hasher, L., \& Tonev, S. T. (2006). Distraction as a determinant of processing speed. Psychonomic Bulletin and Review, 13(4), 619-625. https://doi.org/10.3758/BF03193972

Lustig, C., May, C. P., \& Hasher, L. (2001). Working memory span and the role of proactive interference. Journal of Experimental Psychology: General, 130(2), 199-207. https://doi.org/10.1037/0096-3445.130.2.199

Maciokas, J. B., \& Crognale, M. A. (2003). Cognitive and Attentional Changes withAge: Evidence from Attentional Blink Deficits. Experimental Aging Research, 29(2), 137-153. https://doi.org/10.1080/03610730303715

May, C. P., Hasher, L., \& Kane, M. J. (1999). The role of interference in memory span. Memory and Cognition, 27(5), 759-767. https://doi.org/10.3758/BF03198529

McNab, F., Zeidman, P., Rutledge, R. B., Smittenaar, P., Brown, H. R., Adams, R. A., \& Dolan, R. J. (2015). Age-related changes in working memory and the ability to ignore distraction. Proceedings of the National Academy of Sciences of the United States of 
America, 112(20), 6515-6518. https://doi.org/10.1073/pnas.1504162112

Morey, R. D. (2008). Confidence Intervals from Normalized Data: A correction to Cousineau (2005). Tutorials in Quantitative Methods for Psychology, 4(2), 61-64. https://doi.org/10.20982/tqmp.04.2.p061

Nasreddine, Z. S., Phillips, N. A., Bédirian, V., Charbonneau, S., Whitehead, V., Collin, I., ... Chertkow, H. (2005). The Montreal Cognitive Assessment, MoCA: A brief screening tool for mild cognitive impairment. Journal of the American Geriatrics Society, 53(4), 695-699. https://doi.org/10.1111/j.1532-5415.2005.53221.x

Naveh-Benjamin, M., Cowan, N., Kilb, A., \& Chen, Z. (2007). Age-related differences in immediate serial recall: Dissociating chunk formation and capacity. Memory and Cognition, 35(4), 724-737. https://doi.org/10.3758/BF03193310

Navon, D., \& Gopher, D. (1979). On the economy of the human-processing system. Psychological Review, 86(3), 214-255. https://doi.org/10.1037/0033-295X.86.3.214

Nieuwenstein, M. R., \& Wyble, B. (2014). Beyond a mask and against the bottleneck: Retroactive dual-task interference during working memory consolidation of a masked visual target. Journal of Experimental Psychology: General, 143(3), 1409-1427. https://doi.org/10.1037/a0035257

Oberauer, K. (2005). Control of the contents of working memory - A comparison of two paradigms and two age groups. Journal of Experimental Psychology: Learning Memory and Cognition, 31(4), 714-728. https://doi.org/10.1037/0278-7393.31.4.714

Oberauer, K., Lewandowsky, S., Farrell, S., Jarrold, C., \& Greaves, M. (2012). Modeling working memory: An interference model of complex span. Psychonomic Bulletin and 
Review, 19(5), 779-819. https://doi.org/10.3758/s13423-012-0272-4

Peirce, J., Gray, J. R., Simpson, S., MacAskill, M., Höchenberger, R., Sogo, H., ... Lindeløv, J. K. (2019). PsychoPy2: Experiments in behavior made easy. Behavior Research Methods, 51(1), 195-203. https://doi.org/10.3758/s13428-018-01193-y

Raftery, A. E. (1995). Bayesian Model Selection in Social Research. Sociological Methodology, 25, 111. https://doi.org/10.2307/271063

Rhodes, S., Greene, N. R., \& Naveh-Benjamin, M. (2019). Age-related differences in recall and recognition: a meta-analysis. Psychonomic Bulletin and Review, 26(5), 1529-1547. https://doi.org/10.3758/s13423-019-01649-y

Rhodes, S., Jaroslawska, A. J., Doherty, J. M., Belletier, C., Naveh-Benjamin, M., Cowan, N., ... Logie, R. H. (2019). Storage and processing in working memory: Assessing dual-task performance and task prioritization across the adult lifespan. Journal of Experimental Psychology: General, 148(7), 1204-1227. https://doi.org/10.1037/xge0000539

Ricker, T. J., \& Hardman, K. O. (2017). The nature of short-term consolidation in visual working memory. Journal of Experimental Psychology: General, 146(11), 1551-1573. https://doi.org/10.1037/xge0000346

Ricker, T. J., Nieuwenstein, M. R., Bayliss, D. M., \& Barrouillet, P. (2018). Working memory consolidation: Insights from studies on attention and working memory. Annals of the New York Academy of Sciences, 1424(1), 8-18. https://doi.org/10.1111/nyas.13633

Rossetti, H. C., Lacritz, L. H., Cullum, C. M., \& Weiner, M. F. (2011). Normative data for the Montreal Cognitive Assessment (MoCA) in a population-based sample. Neurology, 
$77(13)$, 1272-1275. https://doi.org/10.1212/WNL.0b013e318230208a

Salthouse, T. A. (1991). Mediation of Adult Age Differences in Cognition By Reductions in Working Memory and Speed of Processing. Psychological Science, 2(3), 179-183. https://doi.org/10.1111/j.1467-9280.1991.tb00127.x

Salthouse, T. A. (2015). Individual Differences in Working Memory and Aging. In R. H. Logie \& R. G. Morris (Eds.), Working memory and ageing (pp. 1-20). Hove, UK: Psychology Press.

Salthouse, T. A., \& Babcock, R. L. (1991). Decomposing Adult Age Differences in Working Memory. Developmental Psychology, 27(5), 763-776. https://doi.org/10.1037/0012-1649.27.5.763

Schwarz, G. (1978). Estimating the Dimension of a Model. The Annals of Statistics, 6(2), 461-464. https://doi.org/10.1214/aos/1176344136

Somberg, B. L., \& Salthouse, T. A. (1982). Divided attention abilities in young and old adults. Journal of Experimental Psychology: Human Perception and Performance, 8(5), 651-663. https://doi.org/10.1037/0096-1523.8.5.651

Stevanovski, B., \& Jolicoeur, P. (2007). Visual short-term memory: Central capacity limitations in short-term consolidation. Visual Cognition, 15(5), 532-563. https://doi.org/10.1080/13506280600871917

Tan, L., \& Ward, G. (2008). Rehearsal in immediate serial recall. Psychonomic Bulletin and Review, 15(3), 535-542. https://doi.org/10.3758/PBR.15.3.535

Unsworth, N., \& Engle, R. W. (2007). The nature of individual differences in working memory capacity: Active maintenance in primary memory and controlled search from secondary memory. Psychological Review, 114(1), 104-132. 
https://doi.org/10.1037/0033-295X.114.1.104

Vergauwe, E., Camos, V., \& Barrouillet, P. (2014). The impact of storage on processing: How is information maintained in working memory? Journal of Experimental Psychology: Learning Memory and Cognition, 40(4), 1072-1095. https://doi.org/10.1037/a0035779

Vergauwe, E., Ricker, T. J., Langerock, N., \& Cowan, N. (2019). What do people typically do between list items? The nature of attention-based mnemonic activities depends on task context. Journal of Experimental Psychology: Learning Memory and Cognition, 45(5), 779-794. https://doi.org/10.1037/xlm0000625

Waldron-Perrine, B., \& Axelrod, B. N. (2012). Determining an appropriate cutting score for indication of impairment on the Montreal Cognitive Assessment. International Journal of Geriatric Psychiatry, 27(11), 1189-1194. https://doi.org/10.1002/gps.3768 